\title{
Research on Problems of Fracture Mechanics About the Spur Gears with Cracked Tooth
}

\author{
Zhang Dawei, Wang Shufeng \\ College of Transportation, Shandong University of Science and Technology, Qingdao, China
}

Email address:

ZDWRBL@163.com (Zhang Dawei),wsfsdut@126.com (Wang Shufeng)

To cite this article:

Zhang Dawei, Wang Shufeng. Research on Problems of Fracture Mechanics About the Spur Gears with Cracked Tooth. Advances in Applied Sciences. Vol. 2, No. 6, 2017, pp. 93-99. doi: 10.11648/j.aas.20170206.11

Received: July 12, 2017; Accepted: July 19, 2017; Published: October 30, 2017

\begin{abstract}
Taking the spur gear as the object of study, based on the dynamic analysis of gear transmission system, the dynamic stress intensity factors of cracked gear teeth are studied by using ANSYS software. The calculation of dynamic stress intensity factor is realized by ANSYS parametric design language. Firstly, the involute tooth profile equation and the root transition curve equation of the gear teeth in the rectangular coordinate system are established, and the geometric model of the gear tooth is generated, and the crack is generated at the root of the gear tooth. Then, the mesh is divided and the loads are applied. Finally, the stress intensity factors at different crack depths are calculated and analyzed. The results show that the stress intensity factor varies significantly with the variation that location of the meshing point and the depth of the crack.
\end{abstract}

Keywords: Crack Depth, The Stress Intensity Factor, Crack Tip, ANSYS Parametric Design Language (APDL)

\section{Introduction}

Gear driving is one of the main transmission forms in mechanical transmission. It is widely used in industry, agriculture and national defense [1]. In the study of gear drive system [2], the gear tooth crack is found and the stress intensity factor at the crack tip is calculated. The variation law of stress intensity factor is analyzed when the load is applied at different meshing points.

In recent years, research on gear fracture at home and abroad has achieved certain results. Wu Jinliang, Wang Zhonghou and Li Guang [3] explored the crack propagation path, and predicted the failure characteristics of crack propagation in the central tooth root and its crack propagation life by using FRANC3D software. Liu Xinbo, Zeng Xiaosong and Liu Yong [4] studied the root of the fatigue crack growth characteristics, and obtained the stress intensity factors at different positions. Wan Zhiguo, Zi Yanyang and Cao Hongrui [5] calculated the stress intensity factor for the spur gear with an initial crack and analyzed the opening angle of the tooth crack in view of the maximum tensile stress (MTS) criterion. Yang Shenghua [6] studied mining machinery gear tooth fracture process and analyzed variation of stress intensity factor of the gear root with crack depth and tooth fracture path by finite element method.
Based on the ANSYS crack-analysis module, Ting Zou et al. [7] investigated the effects of G2G2-continuous blending on the stress intensity factor (SIF) for different crack sizes. F. Curà et al. [8] has considered the stress field at the tooth root fillet and near the crack to evaluate the crack initiation point and to explain the propagation direction. In the early 1920s, British physicist Griffith [9] used the energy balance principle to explain the quantitative relationship between the actual strength of glass and ceramics and the size of micro-cracks. In 1996, S. Glodez, Z. Ren and J. Flashker [10] investigated the fracture and crack propagation characteristics of gear surface by experiments. In addition, many experts and scholars have analyzed the rules of crack initiation and propagation from the point of view of metal physics and microscopic fracture. Foreign scholars have studied the fracture parameters of the tooth root by numerical method, which namely the boundary element method or finite element method, crack tip was divided into several zones, and the boundary conditions were applied. By calculating program, the stress intensity factor of the crack tip is approximately calculated, and the stress and strain field is obtained, thus the fracture characteristics are studied.

Generally speaking, foreign experts [11] have studied the stress intensity factor of the root crack from different angles. However, little research has been done on crack propagation. 
There are few studies on the fracture characteristics of the tooth root in China. From the point of view of linear elastic fracture mechanics, the fracture mechanics characteristics by ANSYS software are less, which is the starting point of this thesis.

\section{Gear Dynamics Analysis}

\subsection{Gear Dynamics Model}

Essentially, the gear system is actually a continuous elastic system. The continuous elastic system is reduced to a discrete elastic system, so the mathematical models are ordinary differential equations. Theoretically, the gear drive is stable. In fact, due to the error of gear and the change of gear meshing stiffness, the vibration of the gear can be aroused. Thereby producing noise and motivating the machine vibration. Neglecting the transverse and axial elastic deformation of the transmission shaft and the elastic deformation of the supporting system, the torsional vibration of the gear is considered only. The lumped mass method [12] is used to establish the torsional vibration analysis model of the gear pair, as shown in figure 1:

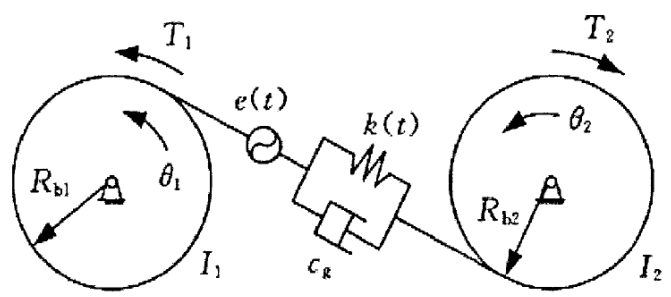

Figure 1. Gear dynamics model.

where $\theta_{i}(i=1,2)$ are torsional vibration displacement of the main and passive gear, respectively; $I_{i}(i=1,2)$ are the rotating inertia of the main and passive gear, respectively; $R_{b i}(i=1,2)$ are the base circle radius of the main and passive gear, respectively; $C_{g}$ is the meshing damping of gear pair; $e(t)$ is the meshing comprehensive error of the gear; $k(t)$ is the meshing comprehensive stiffness of gear pair; $T_{i}(i=1,2)$ are torque acting on the main and passive gears, respectively.

According to Newton's law, without considering the error of gear profile, the differential equation [13] of gear vibration is as follow:

$$
\left.\begin{array}{l}
I_{1} \ddot{\theta}_{1}+c_{g} R_{b 1}\left(R_{b 1} \dot{\theta}_{1}-R_{b 2} \dot{\theta}_{2}-\dot{e}(t)\right)+ \\
k(t) R_{b 1} f\left(R_{b 1} \theta_{1}-R_{b 2} \theta_{2}-e(t)\right)=T_{1} \\
I_{2} \ddot{\theta}_{2}+c_{g} R_{b 2}\left(R_{b 1} \dot{\theta}_{1}-R_{b 2} \dot{\theta}_{2}-\dot{e}(t)\right)+ \\
k(t) R_{b 2} f\left(R_{b 1} \theta_{1}-R_{b 2} \theta_{2}-e(t)\right)=-T_{2}
\end{array}\right\}
$$

The meshing force [14] between gears is mainly composed of the elastic meshing force caused by time-varying meshing stiffness, that is, the dynamic load of gear drive and the viscous meshing force caused by meshing damping. It is assumed that the elastic meshing force is $F_{P}$, and the viscous meshing force is $F_{D}$.

$$
\left.\begin{array}{l}
F_{P}=k(t) f\left(R_{b 1} \theta_{1}-R_{b 2} \theta_{2}-e(t)\right) \\
F_{D}=c_{g}\left(R_{b 1} \dot{\theta}_{1}-R_{b 2} \dot{\theta}_{2}-\dot{e}(t)\right)
\end{array}\right\}
$$

In order to eliminate the displacement of rigid body and normalize the dimension of the system, the relative displacement of the gear meshing line is introduced as the generalized coordinate:

$$
\left.\begin{array}{l}
x=\left(R_{b 1} \theta_{1}-R_{b 2} \theta_{2}-e(t)\right) / b_{c} \\
\omega_{n}=\sqrt{k_{a v}} / m_{g} \\
m_{g}=m_{1} m_{2} /\left(m_{1}+m_{2}\right)
\end{array}\right\}
$$

where $b_{c}$ is given nominal dimension; $\omega_{n}$ is the natural frequency of the system; $m_{g}$ is the equivalent mass of the gear pair; $m_{1}, m_{2}$ are the quality of the main and passive gear, respectively; $k_{a v}$ is the mean meshing stiffness.

\subsection{Calculation of Gear Dynamic Load}

Theoretically, as long as the coincidence degree [1] is 1 (that is $\varepsilon_{\alpha}=1$ ), the transmission of constant gear ratio of the gear can be ensured. But in engineering, there is an error in the manufacture and installation of gears. In order to ensure the continuity of the gear drive, the coincidence ratio of the calculation should be greater than 1 . The dynamic load of gear can be obtained by the law of single and double meshing and the variation law of dynamic load on the meshing line. The variation law of dynamic load of gear teeth with meshing time is shown in figure 2 :

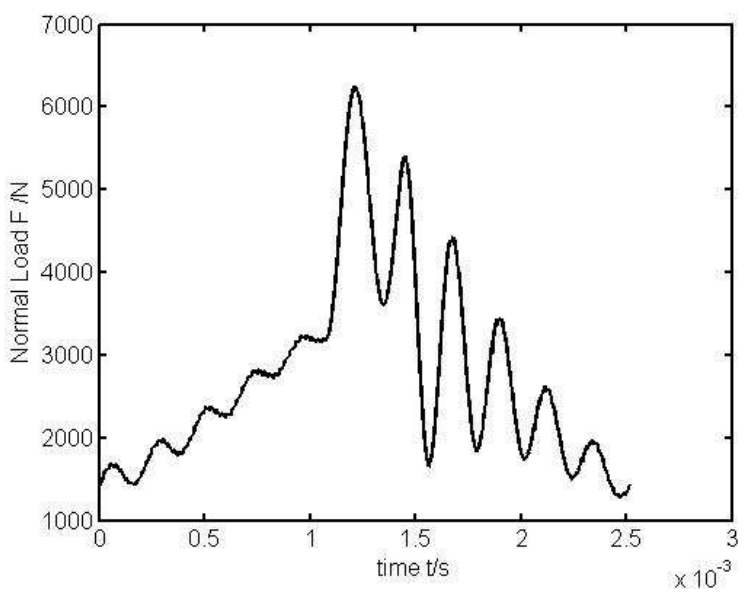

Figure 2. The variation law of dynamic load of gear teeth with meshing time. 


\section{Fracture Mechanics Analysis of Cracked Gear Teeth Based on Dynamic Analysis}

In order to improve the reliability and service life of gears in transmission system, it is necessary to study the fracture phenomenon at the root of gear. From the point of view of fracture mechanics, the general involute gear is taken as the object of study. According to the variation law of the dynamic load along the meshing line and the load angle of the gear in the process of gear transmission, the stress intensity factor of the cracked gear tooth is analyzed and calculated by using the computer simulation software ANSYS.

\subsection{Establishment of Finite Element Model of Gear}

In the gear analysis process, the gear structure parameters directly determine the transmission characteristics of the gear at work, so it is the first task to establish the geometric model of the gear in analyzing the gear root crack characteristics. The geometric model of gear tooth is set up by using APDL parametric language. The main steps are as follows:

(1) Initializing the ANSYS system.

(2) Defining gear parameters and assigning values. Such as gear modulus, teeth number, pressure angle, radius of base circle, and also define unit type, real constant, material characteristics, etc.

(3) Entering the preprocessor to start creating geometry models by using the gear parameters. Processing components, such as copy, move, mirror, boolean, and so on.

(4) Dividing the unit mesh. It is general way to partition mesh by using free mesh. The reason for adopting this method is that it can implement mesh partitioning on any topology, and has better adaptability.

The geometric model of the gear part is modeled by direct modeling. The tooth geometry model is constructed as shown in figure 3 .

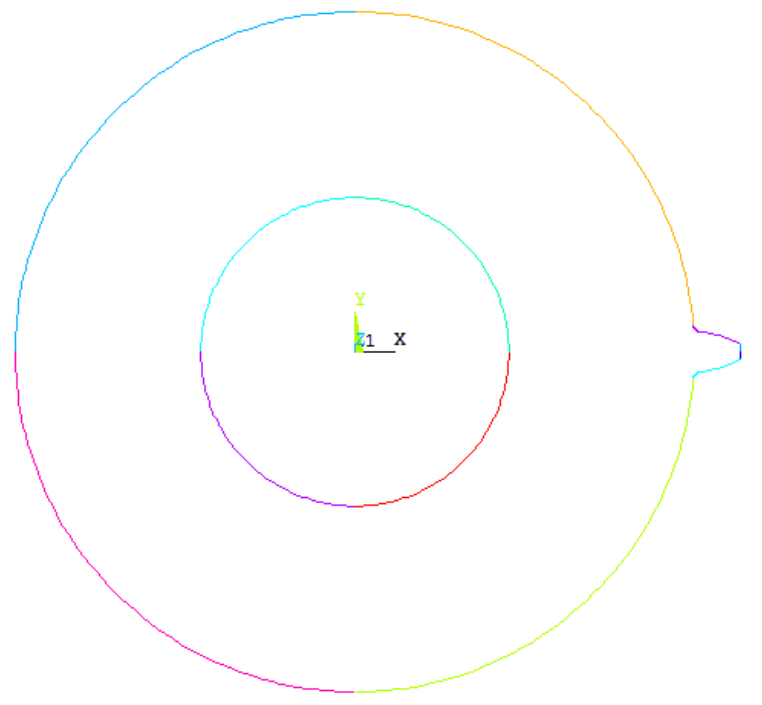

Figure 3. Geometrical model of single tooth gear tooth.

\subsection{Calculation of Stress Intensity Factor in Gear Root Crack}

So far, some scholars have adopted the approximate calculation method [15], which are the boundary element method and the finite element method, when calculating the stress intensity factor at the crack. Because ANSYS software has the function of fracture mechanics analysis, the finite element method has been widely and effectively applied in engineering. The following is to use the analysis module of fracture mechanics in ANSYS software to calculate and solve the stress intensity factor.

\subsubsection{Geometric Model of Root Crack in Gear Teeth}

When calculating the stress intensity factor at the root crack, the root crack model diagram should be firstly established. On the basis of the established gear, the crack at the root of the tooth is opened. The crack depth $(\mathrm{a}=2.5 \mathrm{~mm})$ at the gear root is $2.5 \mathrm{~mm}$ in this time.

\subsubsection{Selection of Singular Element at Crack Tip}

In the linear and elasticity problem, the stress and strain at the crack tip are singular. In order to select the strain singularities, the finite element around the crack tip should be the two singular. The 2D fracture model should use the PLANE2 element, which is a six node triangular cell. The singular element of 2D fracture model is shown in figure 4 :

The first line element around the crack tip must have singularities. The node in each edge of the isoparametric element around the crack tip is usually moved to the $1 / 4$ point at the crack tip. In this way, it can be considered that the singularity of stress at each point of the gear crack tip is simulated, and the stress at the crack tip has this singularity.

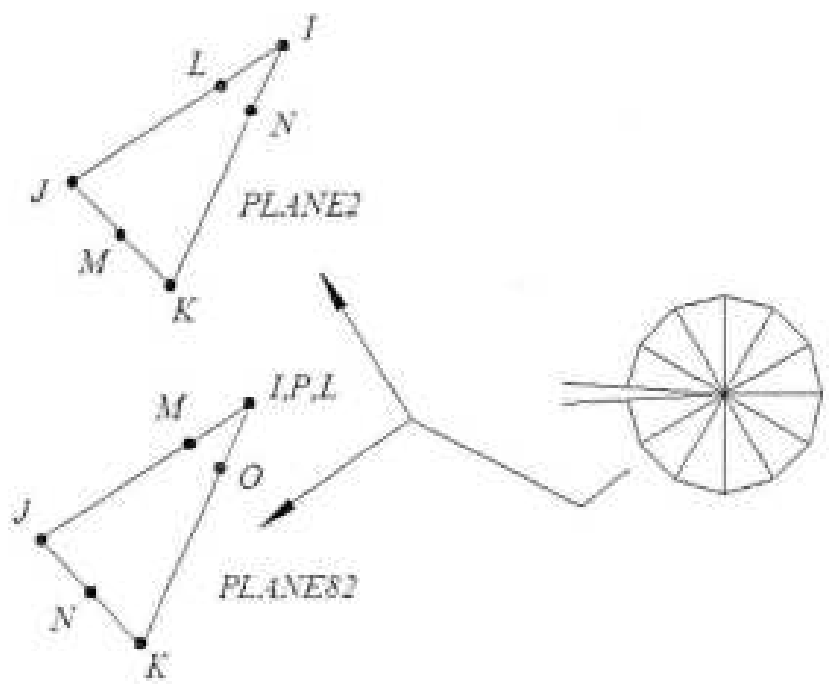

Figure 4. Singular element of 2D fault model.

\subsubsection{Meshing of Crack Tip and Treatment of Boundary Conditions}

Mesh generation: at the tip of the gear tooth crack, the KSCON tip is used to deal with the crack tip. Then, the free mesh is divided and the mesh is automatically raised. The crack tip element processing is shown in figure 5: 
Boundary conditions: the overall gear model is limited to the degree of freedom, the internal gear hole fixed.

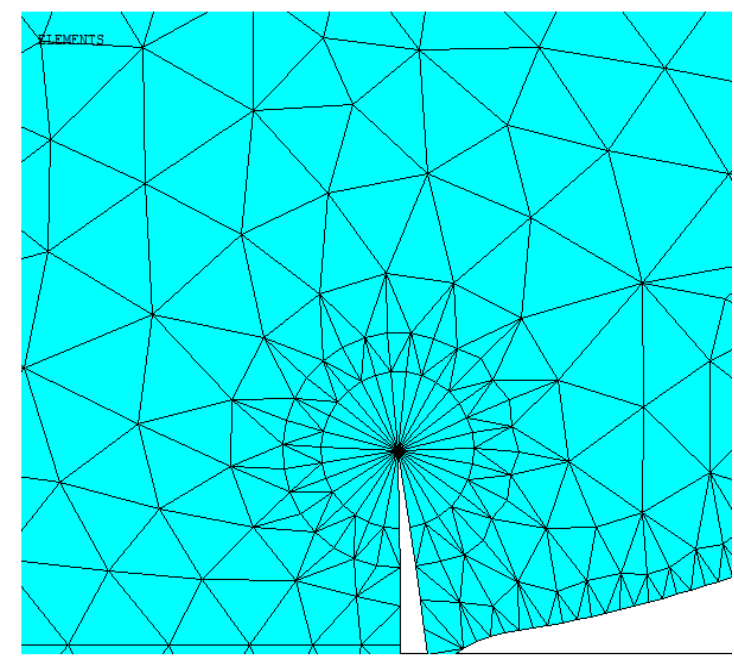

Figure 5. Meshing of the crack tip of the gear teeth.

\subsubsection{Program Computing Using APDL Language and Result Analysis}

After the gear model is built, the crack is first opened on the tooth root and the mesh is divided. Then, the unit is divided, and the gear surface is limited to dynamic loads and boundary conditions are applied. Finally, the APDL language is used to calculate the stress intensity factor at the crack tip of the gear tooth root. The calculation process is as follows:

a. After meshing the mesh, load of the gear surface is applied. The nodes on the gear surface are loaded. The load applied to each node is divided into $\mathrm{X}$ axis, $\mathrm{Y}$ axis direction. Meanwhile, the force is decomposed into two directions.

b. The stress intensity factors under dynamic loads are calculated.

c. The Stress intensity factors are analyzed.

The meshing force is added to the gear tooth surface, and the stress intensity factors are analyzed at different meshing points. When the crack depth $(\mathrm{a}=2.5 \mathrm{~mm})$ is $2.5 \mathrm{~mm}$, the variation of the stress intensity factor of the tooth at the root of the gear tooth during the meshing process is shown in figure 6:

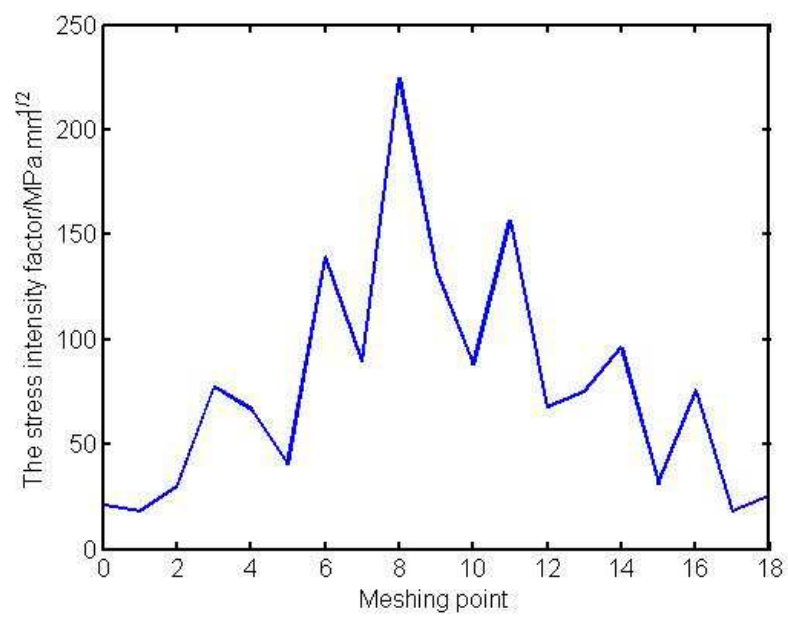

Figure 6. Variation of stress intensity factor during meshing process.
The following conclusions can be drawn from the figure:

(1) In the meshing process of gear teeth, the stress intensity factor at the crack of the root tooth changes continuously with the change of the meshing point;

(2) The maximum value of the stress intensity factor appears in the single tooth meshing zone, which is basically consistent with the position of the maximum meshing force;

(3) The calculated stress intensity factor is similar to the trend of the meshing force, showing a trend of increasing first and reaching the maximum and then decreasing.

\subsection{Calculation of Stress Intensity Factors at Different Crack Depths}

In the above discussion, the variation of stress intensity factor in the process of gear engagement is calculated under the condition of a crack depth. However, the crack propagation will appear after the gear crack is generated. In the following work, the change of stress intensity factor under different crack depth is introduced. Specific gear parameters are shown in table 1 :

Table 1. Basic parameters of gear.

\begin{tabular}{ll}
\hline Parameter & Value \\
\hline Modulus $(\mathrm{mm})$ & 4 \\
Tooth number & 36 \\
Pressure angle(degree) & 20 \\
Radius of reference circle $(\mathrm{mm})$ & 72 \\
Radius of addendum circle $(\mathrm{mm})$ & 76 \\
Radius of dedendum circle $(\mathrm{mm})$ & 67 \\
Modulus of elasticity $(\mathrm{Pa})$ & $2.06 \times 10^{11}$ \\
Poisson's ratio & 0.3 \\
\hline
\end{tabular}

In order to facilitate the establishment of different depth of gear teeth, on the basis of APDL language modeling, a single tooth is taken as the object of study, and the crack of the gear root is opened with three key points, as shown in figure 7 :

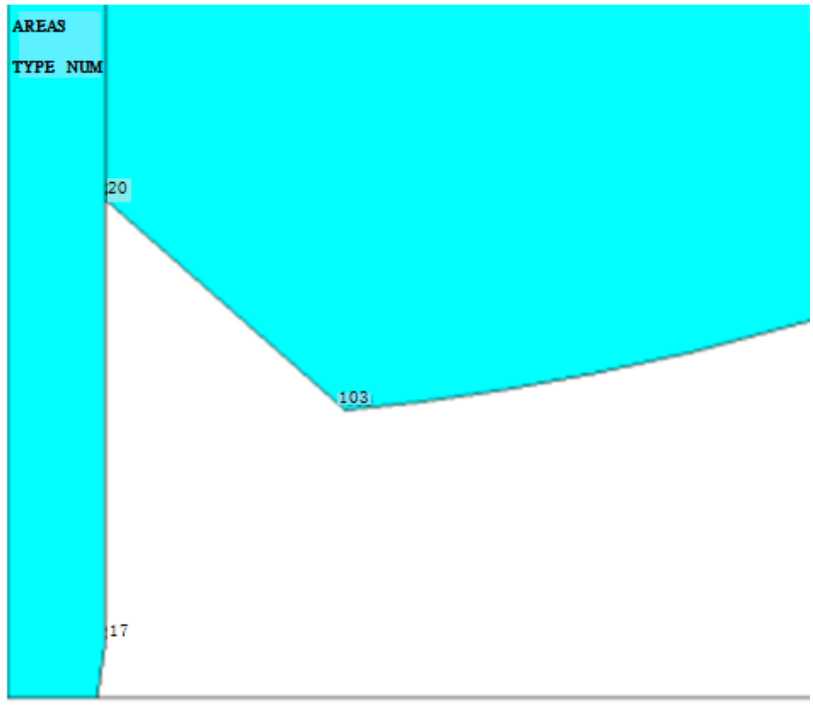

Figure 7. Diagram of gear tooth crack.

As shown in figure 7, the crack depth is mainly determined by the coordinate values of three key points of 17,103 and 20 . 
In this paper, it is assumed that the width of the gear crack is constant, and that the change is the depth of the crack. Therefore, the coordinate values of 17 point and 103 point are constant, and the value of 20 point is changed to control the depth of the crack.

By applying the method of the stress intensity factor

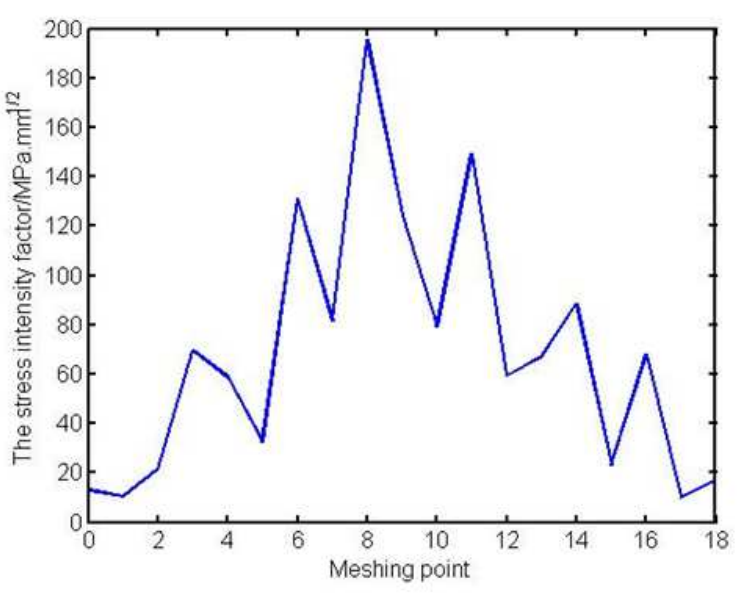

$\mathrm{a}=1.0 \mathrm{~mm}$

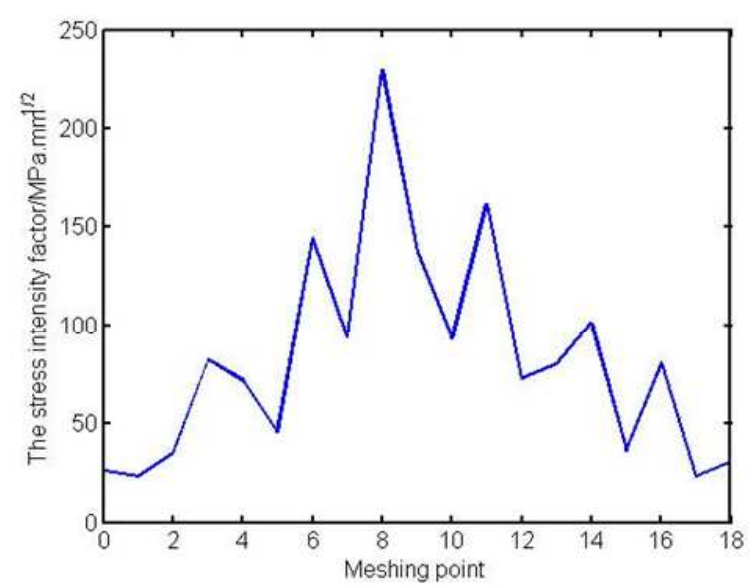

$\mathrm{a}=3.5 \mathrm{~mm}$

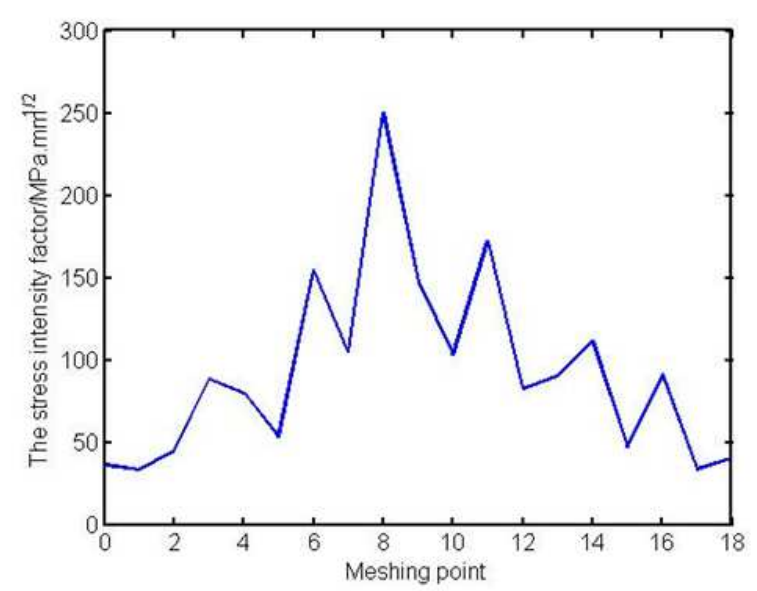

$\mathrm{a}=5.0 \mathrm{~mm}$ calculated above, dynamic loads are applied to the gears at different crack depths. APDL programming language is used to load the meshing line of tooth face, and the stress intensity factor at different crack tip is obtained. The results are shown in figure 8 :
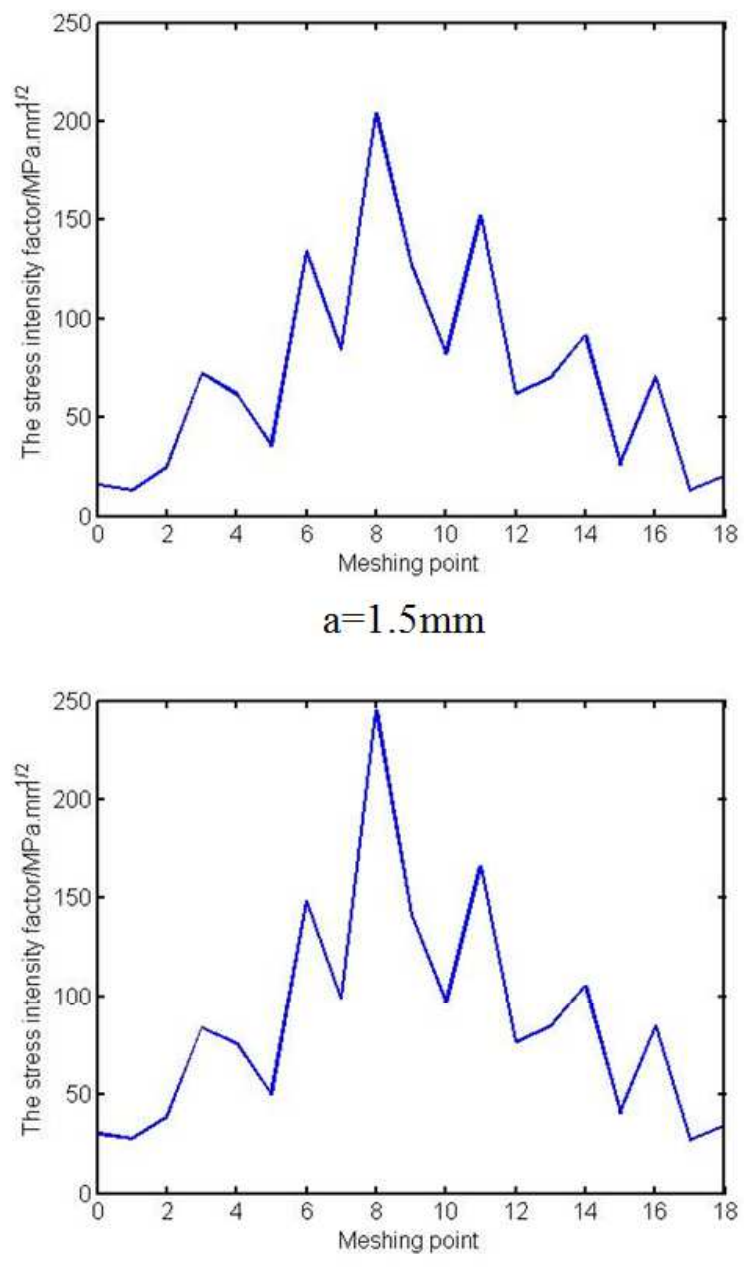

$\mathrm{a}=4.0 \mathrm{~mm}$

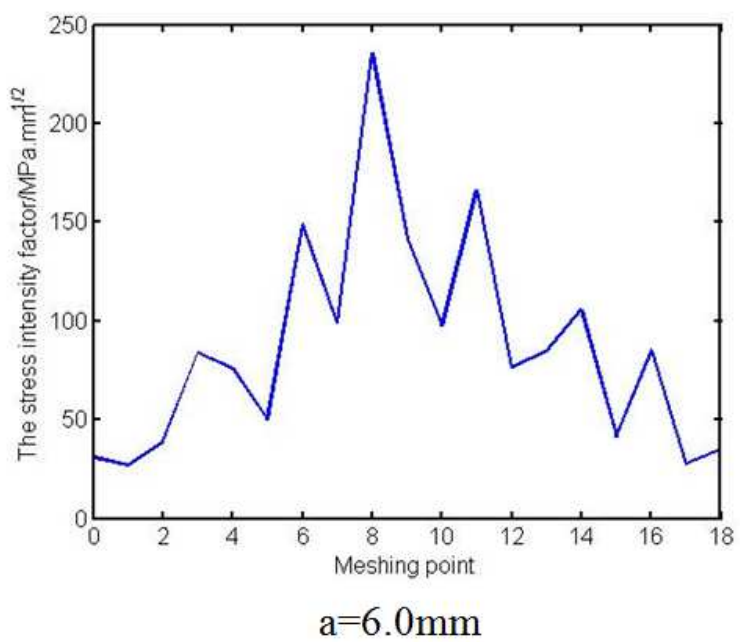

Figure 8. Variation of stress intensity factor with crack depth. 


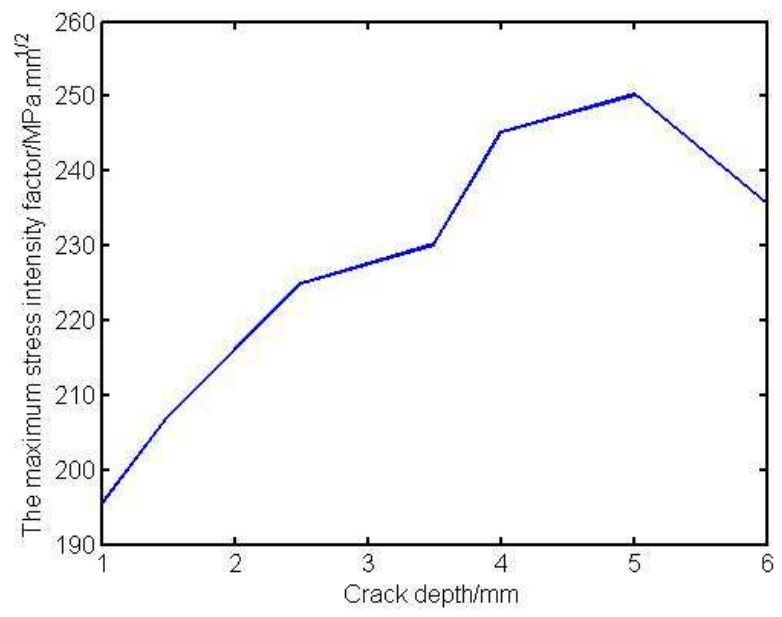

Figure 9. Variation of the maximum stress intensity factor of different crack depth.

It can be seen from figure 8 that the stress intensity factor at the crack tip shows an increasing trend as the crack depth deepens from the variation of stress intensity factor at different crack depths. From the above trends, it can be seen that the stress intensity factor reaches its maximum value and then drops suddenly. Why this phenomenon appears is that the critical crack value has been reached and the crack no longer expands, or fracture damage has occurred.

The maximum value of stress intensity factor in different crack depths is extracted, and then plotted into curves. The trend of stress intensity factor can be clearly seen. The maximum change curve of stress intensity factor at crack is shown in figure 9:

It can be seen from the figure that the dynamic load is loaded on the meshing line of the tooth surface, and the change trend of the stress intensity factor at the tip of the crack at the root is a gradual increase process. When the critical crack depth is to be reached, the stress intensity factor increases to the maximum and then increase gradually. Generally speaking, when the crack begins to expand, the stress intensity factor needs to be increased in order to make the crack continue to expand. If the stress intensity factor is increased, the external load should be increased. Therefore, variation of the stress intensity factor is closely related to the dynamic force of the gear teeth. The stress intensity factor varies significantly with the variation that the location of the meshing point and the depth of the crack.

\section{Conclusion}

In this paper, the APDL parametric language in the finite element ANSYS software is used to calculate the stress intensity factor of the cracked gear teeth. Meanwhile, the relationships between stress intensity factor and crack depth at the root of gear are studied under different crack depth. The variation law of stress intensity factor is plotted by MATLAB software. The results show that the change of the stress intensity factor is closely related to the dynamic force of the gear, and the stress intensity factor varies significantly with the variation that location of the meshing point and the depth of the crack. The research results laid the foundation for the research of the fracture of the tooth root, have a certain theoretical significance for the study of gear fracture mechanics. The results could be applied to calculate fracture strength and predict remaining life of the gear with cracked tooth, and is available for fault diagnosis on the gear transmission with cracked tooth.

\section{Acknowledgements}

This work supported by the Key Research and Development Program of Shandong province (2016 GGX 105008) and Scientific Research Foundation of Shandong University of Science and Technology for Recruited Talents (2015 RCJJ 035 and 2015 RCJJ 036).

\section{References}

[1] Li Huamin, Han Yuanying. The geometrical principle and calculation of involute gear. China Machine Press, Beijing, China, 1985.

[2] Wu Junrong. Coupled analysis of dynamics and fracture mechanics of cracked gear transmission system. Wuhu: Anhui Polytechnic University, 2012.

[3] Wu Jinliang, Wang Zhonghou, Li Guang. Study on crack propagation characteristics and remaining life of helical gear. Journal of Mechanical Transmission, 2014, 38 (12): 1-4.

[4] Liu Xinbo, Zeng Xiaosong, Liu Yong. Prediction and analysis of bending fatigue crack growth behavior of spur gear. Journal of Mechanical Transmission, 2016, 40 (09): 179-183.

[5] Wan Zhiguo, Zi Yanyang, Cao Hongrui. Gear crack propagation simulation and analysis of mesh stiffness. Applied Mathematics and Mechanics, 2015, 36 (S1): 14-20.

[6] Yang Shenghua. The fracture process simulation and fracture strength of gear tooth in mining machine. Colliery Mechanical \& Electrical Technology, 2004, (05): 35-38.

[7] Ting Zou, Mathew Shaker, Jorge Angeles, Alexei Morozov. An innovative tooth root profile for spur gears and its effect on service life. Meccanica. 2017, 52 (8): 1825-1841.

[8] F. Curà, A. Mura, C. Rosso. Influence of high speed on crack propagation path in thin rim gears. Fatigue \& Fracture of Engineering Materials \& Structures. 2017, 40 (1): 120-129.

[9] ZengTao Chen, B. L. Karihaloo, Shou-Wen Yu. Griffith crack moving along the interface of two dissimilar piezoelectric materials. International Journal of Fracture, 1998, 91 (2): 197-203.

[10] S. Glodez, Z. Ren, J. Flashker. Surface fatigue of gear teeth flanks. Computers and structures. 1999, (73): 475-483.

[11] Gu Hao. Fracture mechanics analysis of involute gear tooth crack. Nanjing: Nanjing University of Aeronautics and Astronautics, 2007.

[12] Shi Haifang, Ren Xin. Mechanical properties of materials. Peking University Press, Beijing, China, 2010. 
[13] Su Cheng, Yin Pengpeng. Analysis of nonlinear dynamics in a spur gear pair system. China Mechanical engineering, 2011, 22 (16): 1922-1928.

[14] Sun Zhimi, Shen Yunwe, Li Hua. Coexistence of stationary and strange attractors in a star gear drive system [J]. Journal of Vibration Engineering, 2003, 16 (2): 242-246.
[15] Ye Xianlei, Si Yajie. Application example of ANSYS engineering analysis software. Tsinghua University Press, Beijing, China, 2003. 